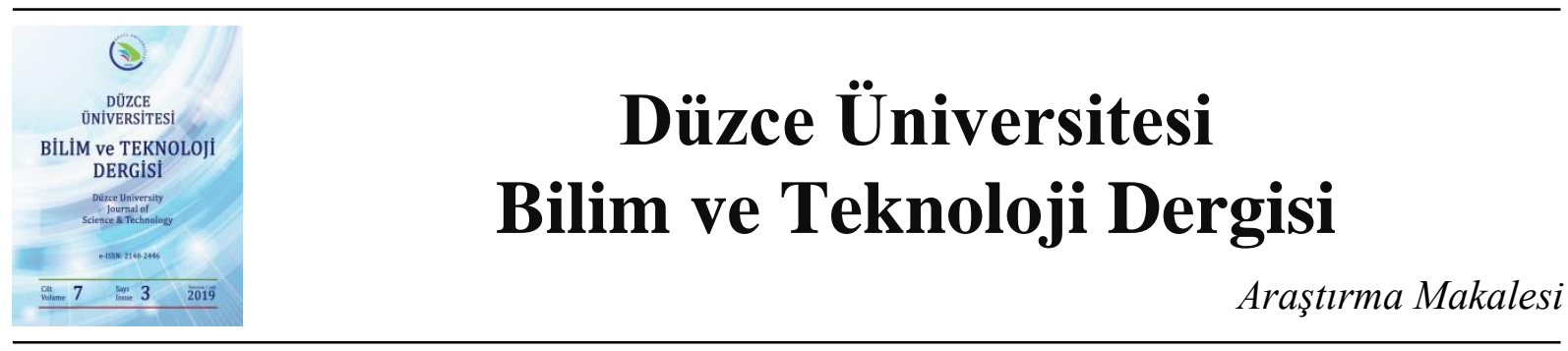

\section{Betonun Dinamik Elastisite Modülü Değerleri Üzerinde Soğuk Derz Etkisinin Araştırılması}

\author{
(iD Bekir Çomak ${ }^{\mathrm{a}}$, iD Özkan Ölmez ${ }^{\mathrm{b}}$, iD Mehmet Emiroğlü ${ }^{\mathrm{a}, *}$ \\ ${ }^{a}$ Inş̧aat Mühendisliği Bölümü, Teknoloji Fakültesi, TÜRKIYE \\ ${ }^{b}$ Inş̧aat Mühendisliği Anabilim Dal, Fen Bilimleri Enstitüsü Düzce Üniversitesi Düzce, TÜRKIYE \\ * Sorumlu yazarin e-posta adresi: mehmetemirogul@duzce.edu.tr \\ DOI : $10.29130 /$ dubited.503777
}

\begin{abstract}
ÖZET
Tahribatsız test metotları, yapıların yerinde (inşaat sahasında) ve taşııııı elemanlara hasar vermeksizin muayenesine olanak tanımaktadır. Betonun durabilite performansı ve dinamik yükler altındaki davranışı hakkında bilgi veren dinamik elastisite modülü değeri, tahribatsız yöntemler ile hızlı bir biçimde tespit edilebilmektedir. Beton üretimi esnasında sahada sıkça rastlanılan sorunlardan biri de soğuk derz olayıdır. Bu çalışmada, farklı döküm zamanları kullanılarak yapay olarak oluşturulmuş soğuk derze sahip numunelerin dinamik elastisite modüllerindeki değişim tahribatsız yöntemler kullanılarak ele alınmıştır. Bu kapsamda Referans (serbest döküm), $30^{\circ}, 45^{\circ}$ ve $90^{\circ}$ derz yüzeyine sahip kiriş numuneler üzerinde farklı döküm sürelerinde $(-30,0,+30,+120,+240,+480,+1140$. dakikalarda) numuneler üretilmiştir. Üretimi yapılan kiriş numuneler üzerinde 28 gün kür süresi ardından rezonans frekansı test metodu kullanılarak dinamik elastisite modülü değerleri hesaplanmıştır.
\end{abstract}

Anahtar Kelimeler: Soğuk derz, Döküm yüzey geometrisi, priz süresi, Rezonans frekansl

\section{Investigation of the Effect of Cold Joints on Dynamic Modulus of Elasticity of Concrete}

\begin{abstract}
Non-destructive testing methods allow the structures to be inspected on-site and without damage to structural elements. The dynamic modulus of elasticity value, gives information about the durability performance of concrete and its behavior under dynamic loads, can be determined quickly with non-destructive methods. One of the problems frequently encountered in the field during the production of concrete is the cold joints. In this study, the changes in the dynamic modulus of elasticity values of the samples which have been artificially formed by using different casting times are evaluated by using non-destructive methods. In this context, beam samples were produced with reference (free formation), $30^{\circ}, 45^{\circ}$ and $90^{\circ}$ joint surfaces at different casting times $(-30,0,+30,+120,+240,+480,+1140$ minutes). The dynamic elasticity modulus values were calculated by using resonance frequency test methods after 28 days curing time on the beam samples.
\end{abstract}

Keywords: Cold joints, Casting surface geometry, Setting time, Resonance frequency 


\section{GiRiș}

$\mathrm{B}_{\mathrm{s}}^{\mathrm{a}}$ aşlangıçta plastik kıvamda olan taze beton şekil verilebilir ve yumuşak bir karışımdır. Fakat su ile çimentonun birleşmesi ardından hidratasyon başlamakta, böylece bu plastik kıvamdaki beton giderek katı bir hal almaktadır. Hidratasyon devam ettikçe taze beton sertleşmekte ve şekil verilemez hale gelmektedir. $\mathrm{Bu}$ nedenle, betonun karılması, taşınması, kalıba yerleştirilmesi ve yüzeyinin düzeltilmesi gibi aşamalarının mümkün olduğunca tek seferde ve taze betona şekil verilebilirken yapılması gerekmektedir [1]. Beton dökümü yapıldığı esnada birinci katman priz aldıktan sonra ikinci katmanın dökülmesi durumunda soğuk derz oluşumu meydana gelmektedir. Böylece bu iki katman birlikte çalışmaz hale gelmektedir [2]. Beton teknolojisinde çatlakların ve genleşmelerin önüne geçmek amacıyla kontrollü dilatasyon derzlerinden faydalanılmaktadır. Ancak soğuk derz olayı genellikle kontrolsüz gelişen ve istenmeyen bir durum olarak karşımıza çıkmaktadır [1,3].

Bir yapıda beton döküm işlerinin işin büyüklügüne ve zamana bağlı olarak yekpare biçimde bitirilebilmesi mümkün olmamaktadır. Farklı katmanlar halinde beton dökümü de bazı durumlarda soğuk derz oluşmasına neden olmaktadır. Bir imalat hatası olan soğuk derz, farklı zamanlarda birbirlerinin üzerine ya da yan yana dökülen betonlarda meydana gelmektedir. Eski mevcut betonun ya da en azından prizini almış betonun üzerine ya da yanına ikinci bir beton döküldüğünde bu iki beton birbirine kaynayıp yapışmaz. Bu şekilde iki beton arasında çatlak görünümünde kılcal bir yarık oluşur, buna soğuk derz denir $[4,5]$.

Betonların farklı zamanda dökülmesi, bazen istenmeden (transmikserin gecikmesi, işin ertesi güne sarkması, beton pompasının bozulması, kalıp sisteminin görevini yerine getirememesi vs.), bazen de betonun iki ayrı defada dökülmesinin mecbur olunduğu durumlardan kaynaklanmaktadır. Bu durum özellikle beton kaldırımlar, su kanalları, havuzlar, beton su depoları ve temellerdeki taban ve perde betonlarının iki ayrı defada dökülmeleri nedeniyle oluşmaktadır [6, 7].

Soğuk derz ile oluşan ek yerleri, genellikle yapının zayıf kısımlarıdır. Bu kısımlarda beton elemanın çekme ve eğilmede çekme dayanımı vb. gibi mekanik özellikleri, bir bütün olarak dökülmüş ve homojen bir beton elemana göre daha az olmaktadır. Ayrıca taşıyıcı elemanlar, çevre etkileri nedeniyle bu kısımlardan daha kolay bir şekilde olumsuz olarak etkilenir. Bu nedenle ek yapılacak beton tabakaları arasında kuvvetli bağlantının sağlanması gerekmektedir [8]. Bir yapı elemanında soğuk derz olması durumunda, yapısal talepleri ve hizmet koşullarına bağlı olarak, yapı elemanın ciddi bir şekilde performansını etkileyebilir. Bu nedenle soğuk derze dikkat etmek çok önemlidir. Soğuk derz bulunan bir yap1 elemanı yapısal kapasitesini karşılayamadığı durumlarda, eleman ya onarılmalı ya da güçlendirilmeli veya tamam yıkıp yeniden yapılması işlemleri mali açıdan araştırılmalıdır.

Soğuk derz oluşumundan kaynaklı kusurların tespitinde, gözle muayene, ilgili bölgeden kesit alma yöntemiyle mikroskobik gözlem, ince kesit analizleri, yarma deneyi vs. kullanılmaktadır [9]. Bunun yanında tahribatsız yöntemler de soğuk derz oluşumunun tespiti ve hasar derecesinin tahmininde kullanılan yöntemlerdendir.

Ohdaira ve Masuzawa [10], yapmış oldukları çalışmalarında, soğuk derz tabakasından dolayı beton dayanımında oluşan azalmayı ultrasonik yöntemle tahmin edebilmek için bir deneysel çalışma yapmışlardır. Farklı S/C oranlarında, iki tabaka halinde döküm yaparak, $20 \times 10 \times 20 \mathrm{~cm}$ boyutlarında 6 adet beton numunesi üretmişlerdir. Çalışmada, ilk tabaka döküldükten 6 ve 10 saat sonra ikinci (üsteki) tabaka beton dökülerek soğuk derz oluşumu sağlanmıştır. Numuneler 14 ve 28 gün kür yapıldıktan sonra dayanımda meydana gelen azalmayı belirleyebilmek için numunelerin karşılıklı 
kenarlarından (alt ve üst vb. değişik pozisyonlarda) $68 \mathrm{kHz}$ bir frekans kullanarak ultrasonik ölçümler almışlardır. Test sonuçlarına göre, beton yerleştirilmesi ve inşaat sürecinde optimum çalışma koşullarının belirlenmesinde, beton ek yerlerinin (yani soğuk derz oluşacak yerlerin) incelenebileceği sonucuna varmışlardır. Karşılaştırmalar sonucunda, soğuk derz metodu ve ultrases geçiş süresi deney metodu arasında beton dayanımı belirlenmesinde hemen hemen aynı sonuçlar elde etmişlerdir. Kadyrov ve Yazıcıoğlu [11-13] yapmış oldukları çalışmalarda, soğuk derzin betonun doğrudan çekme, basınç ve eğilme dayanımı üzerine etkilerini araştırmışlardır. Deneysel çalışmalarını TS EN 206-1 standardına göre üretilen C25 sınıfındaki beton numuneleri üzerinde gerçekleştirmişlerdir. 100x200 $\mathrm{mm}$ boyutlarında silindir ve 100x100x500 mm boyutlarında prizma şeklinde hazırlanan beton numunelerde $45^{\circ}$ ve $90^{\circ}$ açılarda soğuk derz oluşturmuşlardır. Numunelerin yarısını döküp 2, 3, 4 ve 6 saat bekleyerek soğuk derz oluşturduktan sonra kalan yarısını dökmek suretiyle deney numunelerini elde etmişlerdir. Hazırlanan numuneler üzerinde doğrudan çekme, basınç ve eğilme dayanımı deneyleri gerçekleştirilmiştir. Elde edilen sonuçlara göre, soğuk derz oluşumunda süre uzadıkça doğrudan çekme ve eğilme dayanımlarında azalma meydana geldiği tespit edilmiş ve bu azalmanın 6 saatten sonra dökülen betonlarda daha da belirgin olduğu belirtilmiştir. Basınç dayanımında ise $45^{\circ}$ açıda dökülen betonlarda çok az azalma olduğu belirtilmiştir [11-13].

Bu çalışmada, soğuk derz oluşumundan kaynaklı hasarların tahmin edilebilmesi amacıyla, tahribatsız deney metotlarından biri olan rezonans frekansı testleri daha önceden yapay olarak oluşturulmuş soğuk derze sahip numunelere uygulanmıştır. Bu amaçla, C25 sınıfında elde edilen bir beton karışımı, soğuk derz olgusunu araştırabilmek amacıyla 100x100x500 mm kiriş numunelerine farklı döküm süreleri ve farklı yüzey geometrileri sağlanacak şekilde dökülmüştür.

\section{MATERYAL Ve Metot}

Deneysel çalışmada, Oyak Bolu Çimento Fabrikası A.Ş.'nin üretmiş olduğu CEM I 42.5 R tipi çimento, ögütülmüş yüksek firın cürufu, süperakışkanlaştırıcı beton katkısı, $19 \mathrm{~mm}$ maksimum dane çapına sahip agrega ve karışım suyu kullanılmıştır. TS 802 (2009)'a göre C25/30 dayanım sınıfında ve TS EN 206-1'de belirtilen S3 (100-150 mm) çökme kıvam sınıfında olacak şekilde tasarlanan beton karışımı üzerinde TS 2987 standardına göre beton priz başlangıç ve bitiş süreleri sırasıyla 330 ve 498 dakika olarak tayin edilmiştir (Şekil 1). Betonun priz süresi belirlendikten sonra, betonlarda soğuk derz oluşturabilmek amaciyla beton priz süresine göre $-30,0,+30,+120,+240,+480,+1140$. dakikalarda ikinci katman beton dökülerek, iki aşamalı beton dökümü gerçekleştirilmiştir. 


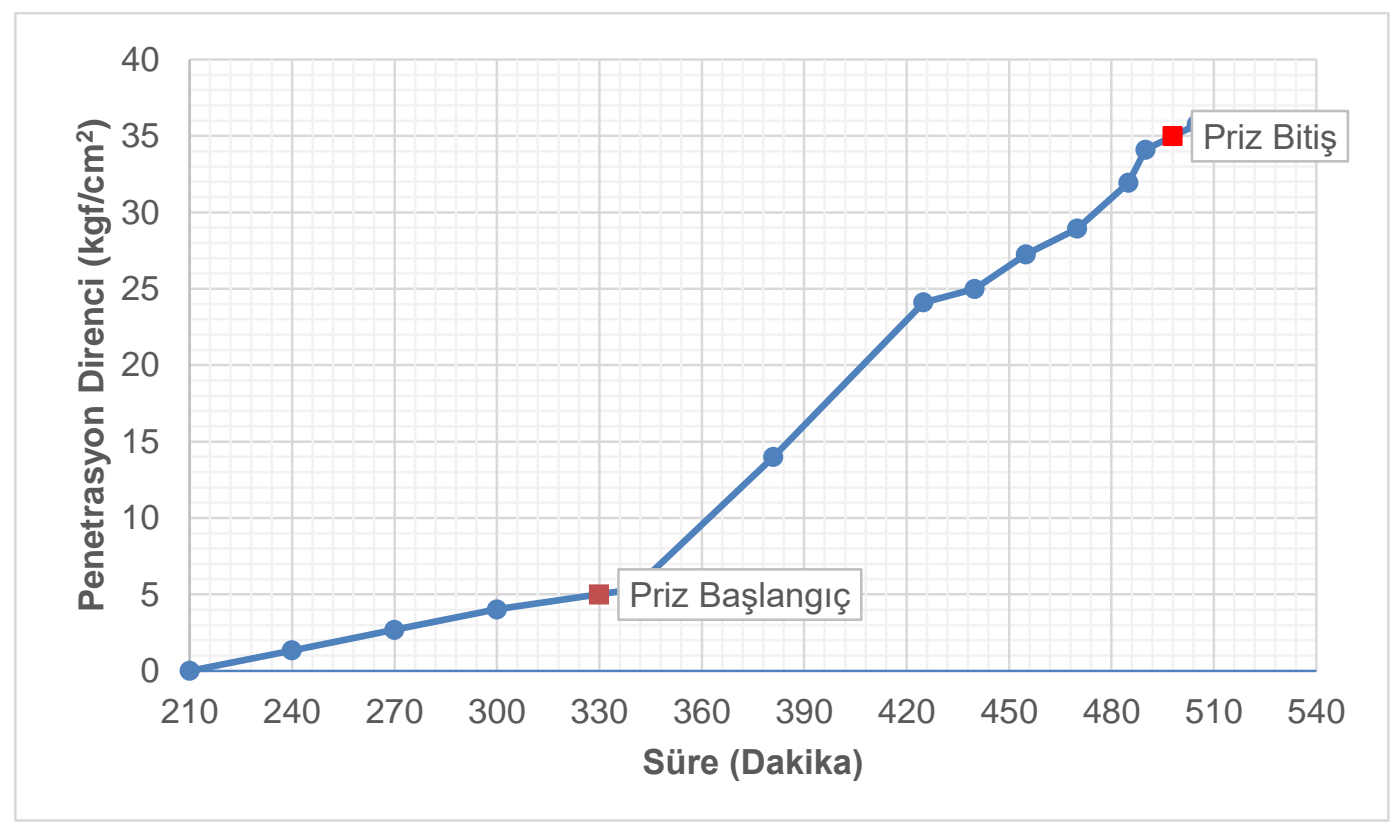

Şekil 1. Üretilen betonun priz başlangıç ve priz bitişs süreleri

Betonun yerleştirilmesi Tablo1'de verilen süreler dikkate alınarak iki tabaka halinde numuneler üretilmiştir. Birinci tabaka beton dökülmüş ve beton prizini aldıktan sonra (498 dakika) özel olarak üretilen beton birleşim geometrisi aparatları çıkarılmış daha sonra Tablo1'deki süreler ilave edilerek ikinci tabaka beton dökümü gerçekleştirilmiştir. İkinci tabaka dökülen beton ile birinci tabaka dökülen beton ile aynı dayanımda (C25/30) dökülmüştür.

Tablo 1. Döküm süreleri ve soğuk derz oluşum aşamaları

\begin{tabular}{lcc}
\multirow{2}{*}{ Döküm Süresi } & \multicolumn{2}{c}{ Betonun Yerleştirilmesi } \\
\cline { 2 - 3 } (Priz Sona Erme Süresine Göre) & I. Tabaka & II. Tabaka \\
\hline - 30. Dakika (Saat) & $\mathrm{C} 25 / 30$ & $\mathrm{C} 25 / 30$ \\
\hline 0. (Saat) & $\mathrm{C} 25 / 30$ & $\mathrm{C} 25 / 30$ \\
\hline 30. Dakika (Saat) & $\mathrm{C} 25 / 30$ & $\mathrm{C} 25 / 30$ \\
120. Dakika (2 Saat) & $\mathrm{C} 25 / 30$ & $\mathrm{C} 25 / 30$ \\
240. Dakika (4 Saat) & $\mathrm{C} 25 / 30$ & $\mathrm{C} 25 / 30$ \\
480. Dakika (8 Saat) & $\mathrm{C} 25 / 30$ & $\mathrm{C} 25 / 30$ \\
1440. Dakika (1 Gün) & $\mathrm{C} 25 / 30$ & $\mathrm{C} 25 / 30$ \\
\hline
\end{tabular}

Kiriş numuneler üzerinde farklı beton birleşim geometrileri oluşturularak (Şekil 2); beton birleşim geometrilerinin soğuk derze olan etkisi araștırılmıștır. Çalışmada biri referans olmak üzere toplam 4 farklı birleşim geometrisinin etkisi karşılaştıılmalı olarak incelenmiştir. Şekil 2'deki numuneleri elde edebilmek için özel olarak üretilen beton birleşim geometrisi aparatları kullanılmıştır (Şekil 3). Bu aparatlar sayesinde $30^{\circ}, 45^{\circ}$ ve $90^{\circ}$ açılı beton yüzeyleri elde edilmiştir. Şekil 2 (a)'da betonun kendi yerleşmesiyle oluşan doğal bitim (referans) şekli kullanılmıştır. 


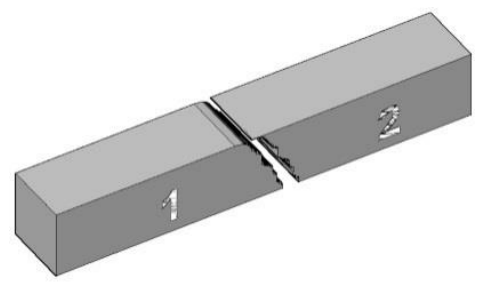

a) Serbest Döküm Yüzeyi (Doğal Birleşim)

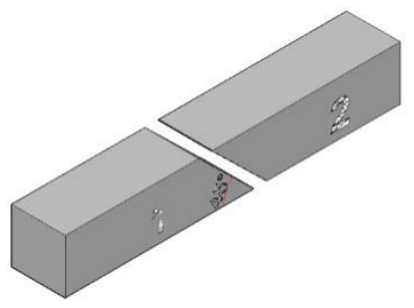

c) $45^{\circ}$ Ĕgimli Birleşim

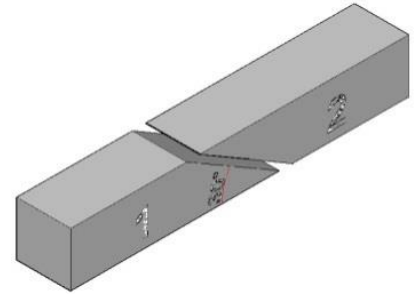

b) $30^{\circ}$ Ĕgimli Birleşim

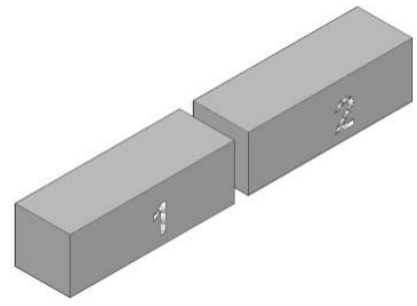

d) $90^{\circ}$ Ĕğimli Birleşim

Şekil 2. Beton birleşim geometrileri

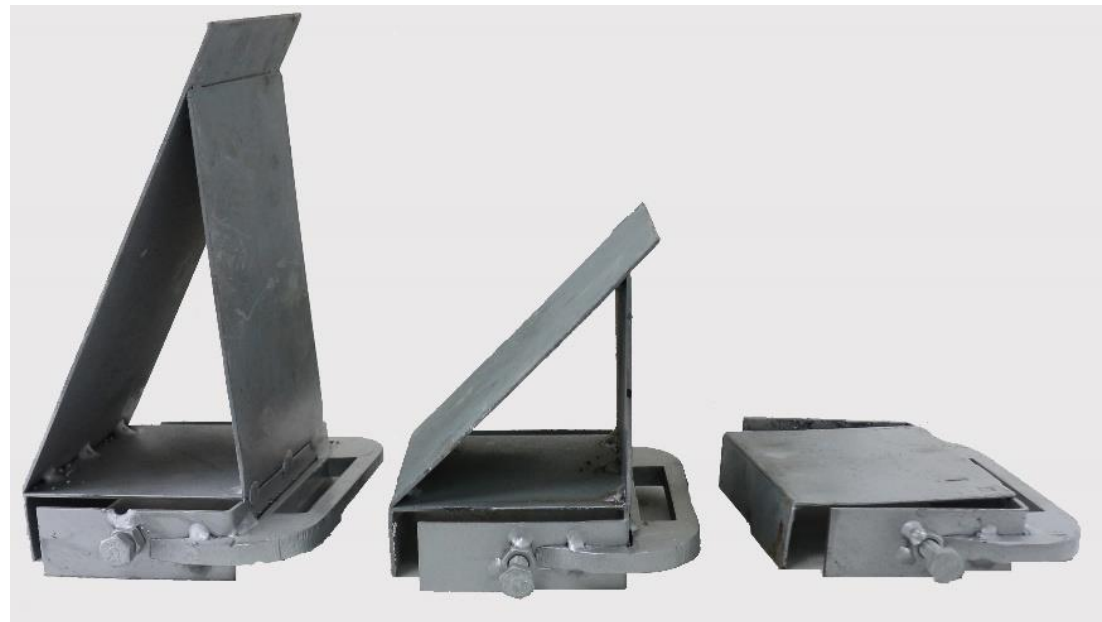

Şekil 3. Soğuk derz oluşturulabilmek için yapılmış ara parçalar

Rezonans frekans1, temel olarak titreşen bir kirişin dinamik elastisite modülü ve yoğunluğu ile ilişkilidir. $\mathrm{Bu}$ sebepten dolayı bir kirişin titreşiminin doğal frekansı, kirişin dinamik elastisite modülünün belirlenmesinde kullanılır. $100 \times 100 \times 500 \mathrm{~mm}$ boyutlarındaki kiriş numunelerinin boyuna test metoduyla elastisite modülü ASTM C 215 standardına göre belirlenmiştir (ASTM C215, 2014). Test metotunun ölçüm şekli Şekil 4'de verilmiştir. 


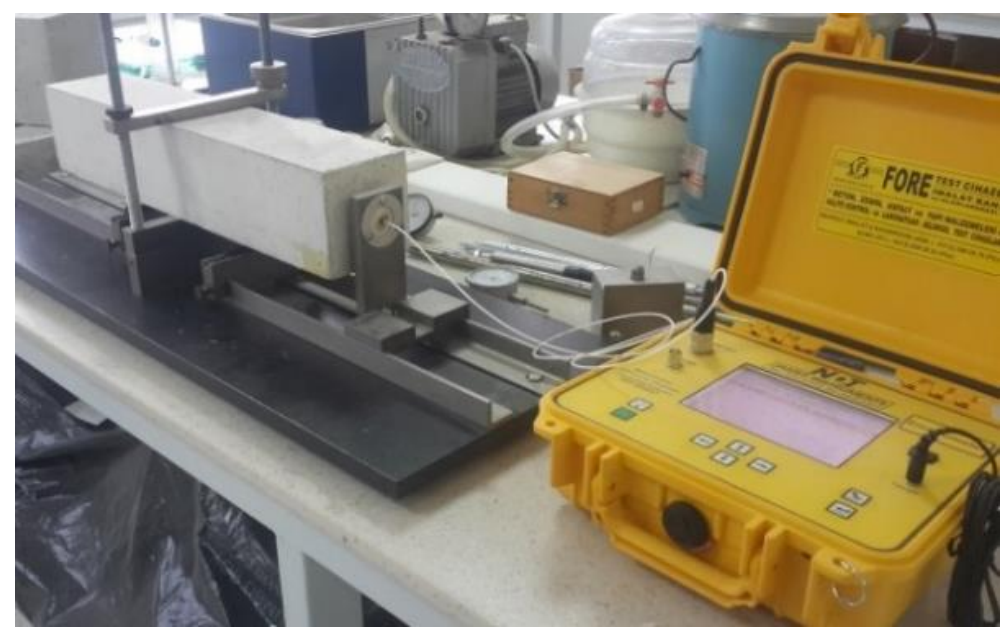

Şekil 4. Rezonans frekansı ölçümleri

\section{BULGULAR VE TARTISMMA}

Çalışmada kullanılan betonun fiziksel ve mekanik özellikleri Tablo 2’ de verilmiştir.

Tablo 2. Çalışmada kullanılan betonun fiziksel ve mekanik özellikleri

\begin{tabular}{|l|c|c|l|c|}
\hline \multicolumn{2}{|l|}{ Basınç Dayanımı (MPa) 7 Günlük } & 32,53 & Boyuna Dinamik Elastiste Modülü (Gpa) & 32,1 \\
\hline $\begin{array}{l}\text { Basıç Dayanımı (MPa) 14 } \\
\text { Günlük }\end{array}$ & 36,77 & Beton Yoğunluğu Islak (kg/m3) & 2356,0 \\
\hline $\begin{array}{l}\text { Basıç Dayanımı (MPa) 28 } \\
\text { Günlük }\end{array}$ & 41,57 & Beton Yoğunluğu Kuru (kg/m3) & 2279,3 \\
\hline Yarmada Çekme Dayanımı (MPa) & 4,04 & Su emme (\%) & 3,4 \\
\hline Pull- off Çekme Dayanımı (MPa) & 2,28 & Priz Başlangıç & 330 Dakika \\
\hline $\begin{array}{l}\text { Doğrudan Çekme Dayanımı } \\
\text { (MPa) }\end{array}$ & 1.97 & Priz Bitiş & 498 Dakika \\
\hline Eğilmede Çekme Dayanımı (MPa) & 6,81 & Not: Değerler ortalamadır. & \\
\hline
\end{tabular}

28 günlük basınç dayanımı deney sonuçları TS 206-1'e uygun olarak değerlendirildiğinde üretilen betonun C30/37 dayanım sınıfında olduğu tespit edilmiştir (Tablo 2). Boyuna dinamik elastisite modülleri ASTM C 215 standardına göre belirlenmiştir (ASTM C215, 2014). Dinamik elastisite modülü deney sonuçları Tablo 3 ve Şekil 5'de verilmiştir

Tablo 3. Boyuna dinamik elastiste modülü değerleri

Soğuk Derz Süresi

\section{-30 Dakika}

0 Dakika

30 Dakika

120 Dakika

240 Dakika

480 Dakika

1440 Dakika

Boyuna Dinamik Elastisite Modülü (Gpa)

\begin{tabular}{cccc}
\hline Serbest & 30 Derece & 45 Derece & 90 Derece \\
\hline 35.2 & 35.5 & 36.3 & 34.3 \\
35.2 & 34.1 & 34.7 & 33.2 \\
34.5 & 35.0 & 35.0 & 31.6 \\
36.3 & 36.5 & 36.5 & 32.8 \\
35.6 & 36.3 & 35.8 & 33.3 \\
33.7 & 36.1 & 35.1 & 32.5 \\
32.4 & 34.5 & 34.4 & 22.6 \\
\hline
\end{tabular}




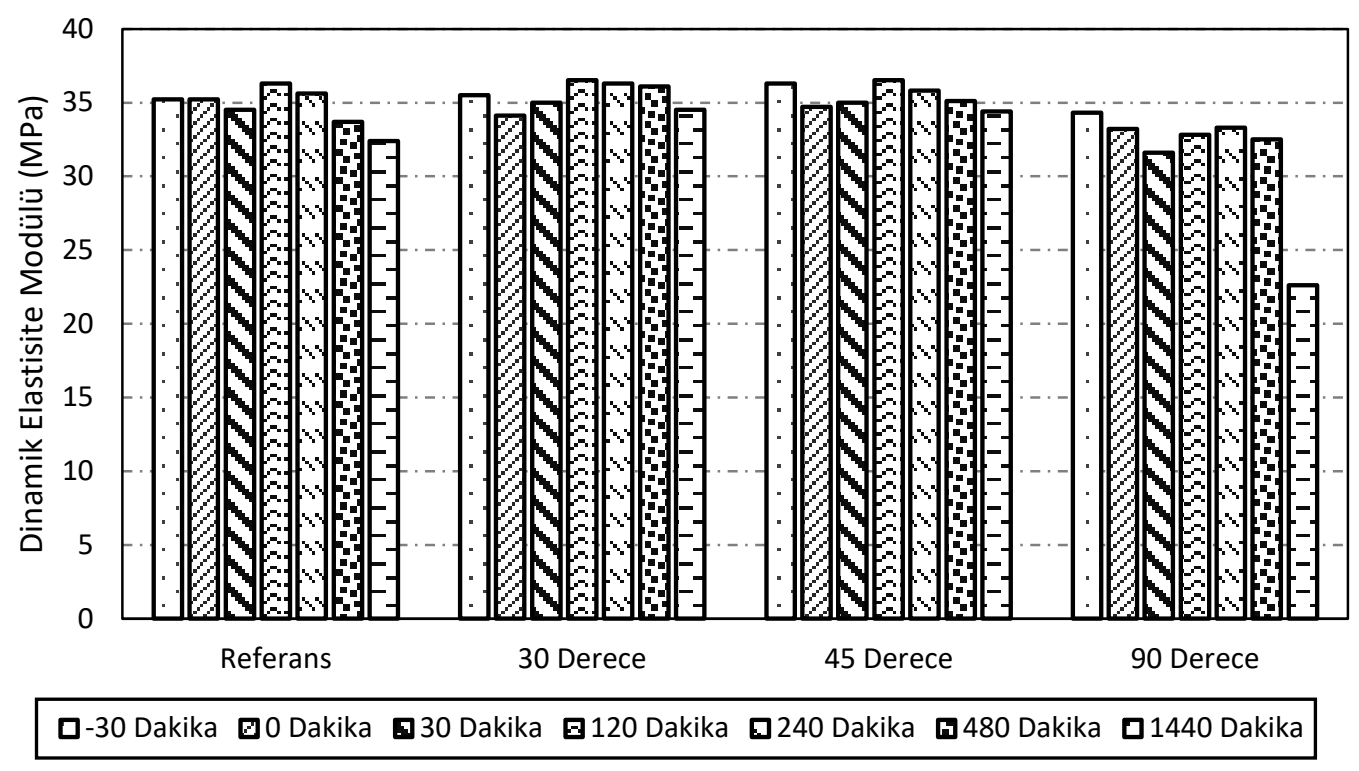

Şekil 5. Boyuna dinamik elastisite modülü deney sonuçları

Şekil 5 incelendiğinde, derz oluşum süresinin artması ile birlikte numunelerin dinamik elastisite modülü değerleri de azalmıştır. Şekil 5'e göre en yüksek dinamik elastisite modülü değerleri priz bitiş süresinden +120 dakikaya kadarki aralıkta meydana gelmiştir. $\mathrm{Bu}$ durumun priz bitiş süresinden +120 dakikaya kadarki sürelerde dökümü yapılacak ikinci tabakanın ilk tabaka ile aderansının daha iyi olmasından kaynaklandığı düşünülmektedir. En düşük dinamik elastisite modülü değerleri ise +1440 dakika sonunda oluşturulan soğuk derz yüzeylerinden elde edilmiştir. Soğuk derz bitim geometrisinin yüzey açısı dikleştikçe dinamik elastisite modülü değerlerinde de düşüş gözlenmiştir. Deney sonuçları incelendiğinde priz bitiş süresi öncesinde ikinci tabakanın dökülmesinin numunelerin rezonans frekansı değerlerinde kayda değer bir değişime neden olmadığı ancak beton priz süresi ardından yapılan dökümlerde (1440 dakika) numunelerin dinamik elastisite modülü değerlerinde önemli azalmalar meydana geldiği gözlenmektedir. $90^{\circ}$ açıya sahip birleşim geometrisinde oluşturulan soğuk derze sahip numunelerin dinamik elastisite modülü değerleri serbest döküm (referans), $30^{\circ}$ ve $45^{\circ}$ lik birleşim geometrisine sahip numunelerin dinamik elastisite modülü değerlerinden daha düşük çıkmıştır. Özellikle priz bitiş süresinden sonra yapılacak dökümlerde (+240 dakika ve sonrası) $30^{\circ}$ ve $45^{\circ}$ 'lik birleşim geometrilerine sahip numunelerin dinamik elastisite modülleri referans ve $90^{\circ}$ 'lik numunelere göre daha yüksek çıkmıştır.

\section{SONUC}

Farkl1 sürelerde soğuk derz oluşumuna müsaade edecek şekilde dökülen numunelerin dinamik elastisite modülü değerlerindeki değişimin araştırıldığı bu çalışmada C25/30 sınıfında hazırlanan betonun priz başlangıç ve bitiş süreleri sırasıyla $330 \mathrm{dk}$ ve $498 \mathrm{dk}$ olarak tespit edilmiştir. 4 farklı birleşim geometrisini temsil edecek şekilde hazırlanan kiriş numunelerinin dinamik elastisite modülü değerleri incelendiğinde, priz bitiş süresinden +120 dakikaya kadarki dökümlerin değerlerinin yüksek çıktığı tespit edilmiştir. Ayrıca, en düşük dinamik elastisite modülü değerlerinin, priz bitiş süresinden 1440 dakika sonrasında ikinci tabaka dökümü yapılan numunelerde elde edildiği, ikinci tabaka dökümün priz bitiş süresi öncesinde yapılan numunelerin dinamik elastisite modülü değerlerinde 
kayda değer bir değişimin olmadığı tespit edilmiştir. Beton dökümü esnasında soğuk derz durumunun kaçınılmaz olduğu durumlarda iki döküm arasındaki birleşim geometrisinin $30^{\circ}$ ve $45^{\circ}$ lik açılarla yerleşme sağlanacak şekilde önlemler alınması önerilmektedir. Priz bitiş süresinden sonra yapılacak dökümlerde (+240 dakika ve sonrası) bu önlem daha önemli rol oynamaktadır.

TEŞEKKÜR: Bu çalışma Düzce Üniversitesi Bilimsel Araştırma Projeleri tarafından desteklenmiştir (Proje no: DÜBAP 2015.07.05.337).

\section{$\underline{\text { V. KAYNAKLAR }}$}

[1] T.Y. Erdoğan, "Beton”, ODTÜ Geliştirme Vakfı Yayıncılık ve İletişim, 2007.

[2] S. Mindess, J. F. Young, "Concrete" Englewoods Cliffs: Prentice Hall Inc., 1981.

[3] ACI 224.3R-95, "Joints in concrete construction", American Concrete Institute ,USA, 2001.

[4] V. R. Rathi, P. K. Kolase, "Effect of cold joint on strength of concrete" International Journal of Innovative Research in Science, Engineering and Technology, vol. 2, no. 9, pp. 4671-4679, 2013.

[5] A. Torres, A. Ramos-Cañón, F. Prada-Sarmiento, M. Botia-Diaz, "Mechanical behavior of concrete cold joints", Revista Ingeniería de Construcción, vol. 31, no. 3, pp. 151-162, 2016.

[6] L. Corporation, "Surface Treatment Agent for Horizontal Construction Joint", Technical Information. In: Lion Corporation, 2014.

[7] N. Temel, "Soğuk Derzler (Cold Joints)", http://www.temelkimya.com/Default.asp?K=0\&K1= Son Erişim Tarihi: 02 Temmuz (Vol. 28 SRC GoogleScholar) 2014.

[8] T. Baştan, “Soğuk Derz” Beton, İMO İzmir Şubesi Bülteni, 151, 41-42, 2010.

[9] J. S. Volz, C. A. Olson, R. G. Oesterle, \& S. H. Gebler, "Are They Pour Lines or Cold Joints?” Concrete Construction Magazine (Publication No C970369), 1997.

[10] E. Ohdaira, \& N. Masuzawa, "Presuming the strength of concrete cold joint by ultrasound" Paper presented at the 2001 IEEE Ultrasonics Symposium. Proceedings An International Symposium (Cat. No.01CH37263), 2001.

[11] N. Kadyrov, "Soğuk Derzin Betonun Mekanik Özelliklerine Etkisinin Araştırılması” (Yüksek Lisans Yüksek Lisans), Gazi Üniversitesi Ankara, 2015.

[12] N. Kadyrov, \& S. Yazıcıoğlu, "Searching About the Effects of Cold Joints on Direct Tensile Strength" Paper presented at the 2nd International Sustainable Buildings Symposium, Ankara, Türkiye, 2015.

[13] N. Kadyrov, \& S. Yazıcıoğlu, "Research of Cold Joint Effects on the Direct Tensile and Flexural Strength of the Concrete" Journal of Polytechnic, vol. 19, no. 3, pp. 203-210, 2016. 